\title{
Hydrothermal Conversion of Red Mud into Magnetic Adsorbent for Effective Adsorption of Zn(II) in Water
}

\author{
Wenqing Dong ${ }^{1}$, Kun Liang ${ }^{1}$, Yanyi Qin ${ }^{1}$, Huijia Ma ${ }^{1}$, Xuan Zhao ${ }^{1}$, Leilei Zhang ${ }^{1, *}$, \\ Suiyi Zhu ${ }^{1, *}$, Yang Yu ${ }^{2}$, Dejun Bian ${ }^{3}$ and Jiakuan Yang ${ }^{4}$ \\ 1 Science and Technology Innovation Center for Municipal Wastewater Treatment and Water Quality \\ Protection, Northeast Normal University, Changchun 130017, China; dongwq359@nenu.edu.cn (W.D.); \\ liangk281@nenu.edu.cn (K.L.); qinyy169@nenu.edu.cn (Y.Q.); mahj082@nenu.edu.cn (H.M.); \\ zhaox703@nenu.edu.cn (X.Z.) \\ 2 Guangdong Shouhui Lantian Engineering and Technology Corporation, Guangzhou 510075, China; \\ yang_yu_2@yahoo.com \\ 3 Jilin Provincial Key Laboratory of Municipal Wastewater Treatment, Changchun Institute of Technology, \\ Changchun 130021, China; ccgcxybdj@163.com \\ 4 School of Environmental Science and Engineering, Huazhong University of Science and Technology, \\ Wuhan 430074, China; jkyang@hust.edu.cn \\ * Correspondence: zhangll554@nenu.edu.cn (L.Z.); papermanuscript@126.com (S.Z.)
}

Received: 22 February 2019; Accepted: 9 April 2019; Published: 12 April 2019

Featured Application: This approach focused on the direct conversion of andradite-rich red mud to magnetite-containing magnetic adsorbent, which had great potential for recycling Fe-rich solid waste. The produced low-cost magnetic adsorbent demonstrated superior $\mathrm{Zn}$ (II) adsorption in smelting wastewater treatment and could also be used as the low-cost core for coating functional groups in the synthesis of functional magnetic materials.

Abstract: Red mud, a Fe-rich waste generated from the aluminum industry, was recovered as an adsorbent for wastewater treatment. The separation process of red mud from water after adsorption, including centrifugation and filtration, was complicated. This study demonstrated an alternative option to recycle red mud for preparing magnetic adsorbent via a facile hydrothermal route using ascorbic acid as reductant. Red mud is weakly magnetized and consists of andradite, muscovite, hematite, and cancrinite. After hydrothermal treatment, andradite in red mud was reductively dissolved by ascorbic acid, and transformed into magnetite and morimotoite. With increasing hydrothermal temperature, the dissolution of andradite accelerated, and the crystallite size of magnetite increased. When the hydrothermal temperature reached $200{ }^{\circ} \mathrm{C}$, the prepared adsorbent P-200 showed a desirable saturation magnetization of $4.1 \mathrm{Am}^{2} / \mathrm{kg}$, and could be easily magnetically separated from water after adsorption. The maximum adsorption capacity of P-200 for $\mathrm{Zn}^{2+}$ was $89.6 \mathrm{mg} / \mathrm{g}$, which is eight-fold higher than that of the raw red mud. The adsorption of $\mathrm{Zn}^{2+}$ by P-200 fitted the Langmuir model, where cation exchange was the main adsorption mechanism. The average distribution coefficient of $\mathrm{Zn}^{2+}$ at low ppm level was $16.81 \mathrm{~L} / \mathrm{g}$ for P-200, higher than those of the red mud $(0.3 \mathrm{~L} / \mathrm{g})$ and the prepared P-120 $(1.48 \mathrm{~L} / \mathrm{g})$ and P-270 $(5.48 \mathrm{~L} / \mathrm{g})$, demonstrating that P-200 had the best adsorption capacity for $\mathrm{Zn}^{2+}$ and can be served as a practical adsorbent for real-world applications. To our knowledge, this is the first study to report the conversion of red mud into a magnetic adsorbent under mild conditions.

Keywords: red mud; hydrothermal; magnetic adsorbent; heavy metal ions; wastewater treatment 


\section{Introduction}

Red mud is a solid waste and abundantly produced from the treatment of bauxite with sodium hydroxide during $\mathrm{Al}$ extraction. For 1 ton of alumina extracted, approximately 1 to 2 tons of red mud residual is produced [1]. Due to its high calcium and sodium hydroxide contents, red mud is relatively toxic and causes severe environmental pollution and ecological damage [2]. Thus, safe disposal methods have been developed for red mud (including dewatering, drying, and landfilling [3]), which cause additional cost and require regular management.

The resource utilization of red mud could solve its disposal problems [4-8]. Recently, research has focused on utilizing red mud for the removal of toxic heavy metals [9], phosphate [10], and harmful organics [11]. Sahu et al. [9] investigated the pretreatment of red mud by a combined method of $\mathrm{CO}_{2}$ neutralization and calcining at $500{ }^{\circ} \mathrm{C}$, and found that the pretreated red mud showed high adsorption capacity of $\mathrm{Zn}^{2+}(14.9 \mathrm{mg} / \mathrm{g})$. Wang et al. [10] reported that after hydrochloric acid neutralization, the neutralized red mud exhibited higher adsorption capacity for phosphate $(108.6 \mathrm{mg} / \mathrm{g})$ than untreated red mud. However, the separation process of red mud from water after adsorption, including high-speed centrifugation, precipitation, coagulation and/or filtration $[5,9,10]$, was tedious, which limited its application for wastewater treatment. An optimal method to rapidly separate red mud from water was to convert weakly magnetized red mud into magnetically separated adsorbent.

The Fe oxides in red mud can be converted into magnetic magnetite after roasting under addition of pyrite [12], coal [13], or by injecting $\mathrm{H}_{2}$ [14] and methane [15]. Liu et al. [12] reported that part of the Fe oxides in red mud was converted into magnetite with pyrite as exogenous ferrous and reducing regent after calcination at $600{ }^{\circ} \mathrm{C}$. Samouhos et al. [14] reported that $87 \%$ of the hematite $\left(\mathrm{Fe}_{2} \mathrm{O}_{3}\right)$ in red mud was transformed into magnetite after roasting at $480^{\circ} \mathrm{C}$ using $\mathrm{H}_{2}$ as reductant. However, high temperatures were applied in these methods to promote the breakdown of the Fe-O-Si or Fe-O-Al bonds into the form of Fe-O-Fe linkage [16]. The breakdown of Fe-O-Si or Fe-O-Al bonds can be achieved at low temperature [17]. For instance, by adding iron powder, red mud could be converted to magnetite-containing materials after hydrothermal treatment at $260^{\circ} \mathrm{C}$ [18]. However, the obtained magnetite was probably generated from the oxidation of iron powder. Iron-bearing minerals, such as andradite and hematite [6], were abundant in red mud, and can be converted into magnetic minerals by adding reductants under mild condition. However, the phase transformation of Fe-bearing minerals in red mud has not yet been studied.

In this study, red mud was converted into magnetic adsorbent via a facile hydrothermal route using ascorbic acid as reductant. To demonstrate the potential applications of red mud, the ability of the synthesized magnetic adsorbent to remove $\mathrm{Zn}^{2+}$ from water was investigated.

\section{Materials and Methods}

\section{1. $\operatorname{Red} M u d$}

Red mud was acquired from Sanhe Aluminum Co., Ltd. (Yichang, Hubei, China) and vacuum-dried at $55{ }^{\circ} \mathrm{C}$ overnight before use. The main components of red mud as detected by X-ray fluorescence spectrometer (XRF, S4-Explorer, Bruker, Germany) were $\mathrm{CaO}(19.9 \%), \mathrm{Al}_{2} \mathrm{O}_{3}(19.9 \%)$, $\mathrm{SiO}_{2}(17.5 \%), \mathrm{Fe}_{2} \mathrm{O}_{3}(16.6 \%), \mathrm{TiO}_{2}(6.2 \%)$, and $\mathrm{Na}_{2} \mathrm{O}(3.8 \%)$. After red mud was dispersed into water overnight, the $\mathrm{pH}$ of the liquid fraction reached approximately 11.5 , indicating that red mud was alkaline and required stabilization.

\subsection{Synthesis of Magnetic Adsorbent}

Approximately $1 \mathrm{~g}$ of dry red mud was dispersed in $30 \mathrm{~mL} 4 \mathrm{~mol} / \mathrm{L} \mathrm{NaOH}$ to form a brownish suspension. Ascorbic acid was then dumped into the suspension at a molar ratio of ascorbic acid to iron of 2 in the red mud. The suspension was magnetically stirred for $10 \mathrm{~min}$, and then transferred to a Teflon kettle to heat at $120^{\circ} \mathrm{C}$ for $10 \mathrm{~h}$. After cooling down to room temperature, the precipitate was collected and then washed five times with deionized water, followed by vacuum-drying at $50{ }^{\circ} \mathrm{C}$ for 
$24 \mathrm{~h}$. The obtained sample was named P-120. The controls were conducted according to the procedures as described above. In the controls, the hydrothermal temperature was changed from $120^{\circ} \mathrm{C}$ to $200^{\circ} \mathrm{C}$ and $270{ }^{\circ} \mathrm{C}$, and the obtained adsorbents were denoted P-200 and P-270, respectively.

\subsection{Adsorption Experiment}

The adsorption performances of red mud and the prepared adsorbents were investigated using $\mathrm{Zn}^{2+}$ as target. Stock solutions with $\mathrm{Zn}^{2+}$ concentrations in the range of $0-120 \mathrm{mg} / \mathrm{L}$ were prepared, and adjusted to $\mathrm{pH} 4$ by adding $5 \% \mathrm{NaOH}$ and $5 \% \mathrm{HCl} .20 \mathrm{~mL}$ stock solution was mixed with $0.01 \mathrm{~g}$ adsorbent in a series of triangular flasks. The flasks were placed in an incubator (THZ-98C, Shanghai Yiheng) and then shaken at shaken at $150 \mathrm{rpm}$ for $12 \mathrm{~h}$. After adsorption, the obtained magnetic adsorbents P-200 and P-270, respectively, were magnetically separated, while red mud and P-120 were centrifuged at $5500 \mathrm{rpm}$ for $5 \mathrm{~min}$. The concentration of $\mathrm{Zn}^{2+}$ in the supernatant was measured by an inductively coupled plasma emission spectrometer (ICP-OES, Avio 200, PerkinElmer, USA).

The adsorbed amount $\left(q_{\mathrm{e} 1}, \mathrm{mg} / \mathrm{g}\right)$ of $\mathrm{Zn}^{2+}$ was calculated via Equation (1):

$$
q_{\mathrm{e} 1}=\frac{\left(C_{1}-C_{\mathrm{e} 1}\right) \times V}{m_{1}}
$$

where $C_{1}$ and $C_{\mathrm{e} 1}$ represent the initial $\mathrm{Zn}^{2+}$ concentration and the equilibrium concentration $(\mathrm{mg} / \mathrm{L})$ after adsorption, $V$ represents the solution volume $(\mathrm{L})$, and $m_{1}$ represents the adsorbent weight $(\mathrm{g})$.

The $\mathrm{Na}^{+}$concentration in the supernatant was measured using an ion chromatograph (883 Basic, Metrohm, Switzerland) coupled with a C4 cation column (Metrohm, Switzerland). The released amount $\left(q_{\mathrm{e} 2}, \mathrm{mg} / \mathrm{g}\right)$ of $\mathrm{Na}^{+}$was calculated via Equation (2):

$$
q_{\mathrm{e} 2}=\frac{\left(C_{\mathrm{e} 2}-C_{2}\right) \times V}{m_{1}}
$$

where $C_{2}$ and $C_{\mathrm{e} 2}$ represent the initial concentration of $\mathrm{Na}^{+}$in the solution and the equilibrium concentration after adsorption $(\mathrm{mg} / \mathrm{L})$.

\subsection{Surface Site Concentration}

The adsorption of $\mathrm{Zn}^{2+}$ on red mud and P-120, P-200, and P-270 was related to the concentration of surface coordination sites of these adsorbents. The surface site concentrations $\left(H_{\mathrm{S}}\right)$ were measured by a potentiometric titrator (ZDJ-4A, Leici, China). In the titration experiments, $0.1 \mathrm{~g}$ of the adsorbents was mixed with $50 \mathrm{~mL}$ of $0.01 \mathrm{~mol} / \mathrm{L} \mathrm{NaNO}_{3}$ in a conical flask, followed by bubbling with pure $\mathrm{N}_{2}$. After that, the $\mathrm{pH}$ value of the solution was adjusted to 4 with $0.6 \mathrm{~mol} / \mathrm{L}$ nitric acid, and then back-titrated to approximately 10 with $0.3 \mathrm{~mol} / \mathrm{L} \mathrm{NaOH}$.

When nitric acid was added to the solution, a cationic exchange reaction between the $\mathrm{H}^{+}$in the solution and the coordinated cations (denoted as Me, e.g., $\mathrm{Na}^{+}, \mathrm{K}^{+}, \mathrm{Ca}^{2+}$, and $\mathrm{Mg}^{2+}$ ) on the surface coordination sites $\equiv \mathrm{SO}^{-}$( $\mathrm{S}$ represents $\mathrm{Fe}, \mathrm{Si}$, or $\mathrm{Al}$ ) of the adsorbents occurred as shown in Equation (3). Thus, part of the free $\mathrm{H}^{+}$was associated with the coordination sites of the adsorbent. By adding $\mathrm{NaOH}$, the free $\mathrm{H}^{+}$in the liquid fraction was first neutralized with $\mathrm{OH}^{-}$, and then, the coordinated $\mathrm{H}^{+}$on the surface sites $\equiv \mathrm{SO}^{-}$of the adsorbents was replaced by cationic $\mathrm{Na}^{+}$via cationic exchange (Equation (4)). Finally, the $\mathrm{pH}$ of the solution increased due to the addition of overdosed $\mathrm{NaOH}$ :

$$
\begin{aligned}
& \equiv \mathrm{SO}^{-} \mathrm{Me}^{\mathrm{n}+}+\mathrm{H}^{+} \leftrightarrow \equiv \mathrm{SO}^{-} \mathrm{H}^{+}+\mathrm{Me}^{\mathrm{n}+}, \\
& \equiv \mathrm{SO}^{-} \mathrm{H}^{+}+\mathrm{NaOH} \leftrightarrow \equiv \mathrm{SO}^{-} \mathrm{Na}^{+}+\mathrm{H}_{2} \mathrm{O},
\end{aligned}
$$

The Gran function value (denoted as $G$ ) was calculated via Equations (5) and (6):

$$
\text { Under acidic conditions, } G=\left(V_{0}+V_{1}+V_{2}\right) \times 10^{-\mathrm{pH}} \text {, }
$$




$$
\text { Under alkaline conditions, } G=\left(V_{0}+V_{1}+V_{2}\right) \times 10^{-(13.8-\mathrm{pH})} \text {, }
$$

where $V_{0}, V_{1}$, and $V_{2}$ represent the volume $(\mathrm{mL})$ of the initial solution, the titrated $\mathrm{HNO}_{3}$ and $\mathrm{NaOH}$, separately.

The $H_{\mathrm{s}}(\mathrm{mmol} / \mathrm{g})$ of the adsorbents was calculated with the following equation:

$$
H_{s}=\frac{\left(V_{\mathrm{eb} 2}-V_{\mathrm{eb} 1}\right)_{\mathrm{adsorbent}}-\left(V_{\mathrm{eb} 2}-V_{\mathrm{eb} 1}\right)_{\mathrm{blank}}}{m_{2}} \times \mathrm{C}_{\mathrm{NaOH}}
$$

where $V_{\mathrm{eb} 1}$ and $V_{\mathrm{eb} 2}$ represent the volume of the consumed $\mathrm{NaOH}$ for the neutralization of free $\mathrm{H}^{+}$in the liquid solution, and the total $\mathrm{H}^{+}$in the liquid solution and the adsorbents surface; $C_{\mathrm{NaOH}}$ represents the $\mathrm{NaOH}$ concentration $(\mathrm{mol} / \mathrm{L}) ; m_{2}$ represents the adsorbent weight $(\mathrm{g})$.

\subsection{Characteristics}

The crystal structure of red mud and the adsorbents were determined by an X-ray powder diffraction (XRD, RAPID-S, Rigaku, Japan). The saturation magnetization of red mud and the adsorbents were detected by a superconducting quantum interference devices magnetometer (SQUID-VSM, Quantum Design, San Diego, CA, USA). X-ray photoelectron spectroscopy (XPS) measurements were performed with a spectrometer (ADES 400, VG-ADES, UK). The composition of red mud and the adsorbents was analyzed by XRF spectroscopy. The morphology of red mud and the adsorbents were recorded by field-emission scanning electron microscopy (SEM, FE-SEM, FEI Co., Hillsboro, OR, USA).

\section{Results and Discussion}

\subsection{Conversion of Red Mud into Magnetic Adsorbent}

To determine the crystallography of both red mud and the adsorbents, XRD experiments were conducted. The observed peaks in Figure 1 in the red mud indicate the presence of andradite (JCPDS 87-1971), hematite (JCPDS 33-0664), cancrinite (JCPDS 72-2076), clinochlore (79-1270), muscovite (JCPDS 07-0042), and morimotoite (JCPDS 47-1877). After hydrothermal treatment at $120{ }^{\circ} \mathrm{C}$, no apparent change of the XRD pattern of $\mathrm{P}-120$ was observed. When the temperature increased to $200{ }^{\circ} \mathrm{C}$, two typical muscovite peaks at $2 \theta=8.8^{\circ}$ and $26.8^{\circ}$ were not observed and the major peak of andradite at $2 \theta=32.3^{\circ}$ was significantly reduced in the diffraction pattern of P-200. Instead, the peaks of cancrinite, clinochlore, and morimotoite increased. Notably, new peaks at $2 \theta=30.1^{\circ}$ and $35.4^{\circ}$ appeared, which belonged to an inverse spinel magnetite (JCPDS 19-0629) [19]. Those results indicated that the dissolution of muscovite occurred with the temperature increasing from $120^{\circ} \mathrm{C}$ to $200{ }^{\circ} \mathrm{C}$, followed by the reductive dissolution of andradite and hematite with ascorbic acid at a higher temperature.

Ascorbic acid was a typical reductant, and could react with andradite and hematite at room temperature [20,21]; however, the process was inhibited by the Si/Al coating (e.g., amorphous aluminosilicate) [22] on the surface of andradite and hematite. With the temperature increasing form $120^{\circ} \mathrm{C}$ to $200{ }^{\circ} \mathrm{C}$, similar to the dissolution of muscovite in red mud, the Si/Al coating on andradite and hematite was also attacked by hydroxyl with generation of $\mathrm{SiO}_{3}{ }^{2-}$ and $\mathrm{Al}(\mathrm{OH})_{4}{ }^{-}$into the liquid fraction $[23,24]$. Thus, andradite and hematite were exposed to the liquid fraction, and reduced by ascorbic acid. Without adding ascorbic acid, andradite was stable in alkaline conditions, and generated in the presence of cancrinite and hematite during the hydrothermal treatment of red mud [25].

In the hydrothermal process, $\mathrm{Si}, \mathrm{Al}$ and $\mathrm{Fe}$ from the dissolution of muscovite, andradite, and hematite were involved in the recrystallization of $\mathrm{Fe}^{2+}$-containing minerals, such as morimotoite, clinochlore, and magnetite. With the absence of $\mathrm{Fe}^{2+}, \mathrm{Si}$ and $\mathrm{Al}$ were recrystallized in the form of cancrinite, which was in agreement with the report of Zhang et al. [26]. The cages of cancrinite's 12-membered ring channels conferred it enough sites for anions coordination [27] and preferentially 
selected $\mathrm{CO}_{3}{ }^{2-}$ as structure stabilizer over $\mathrm{OH}^{-}$[28] when the former was generated from the oxidation of ascorbic acid and present in solution.

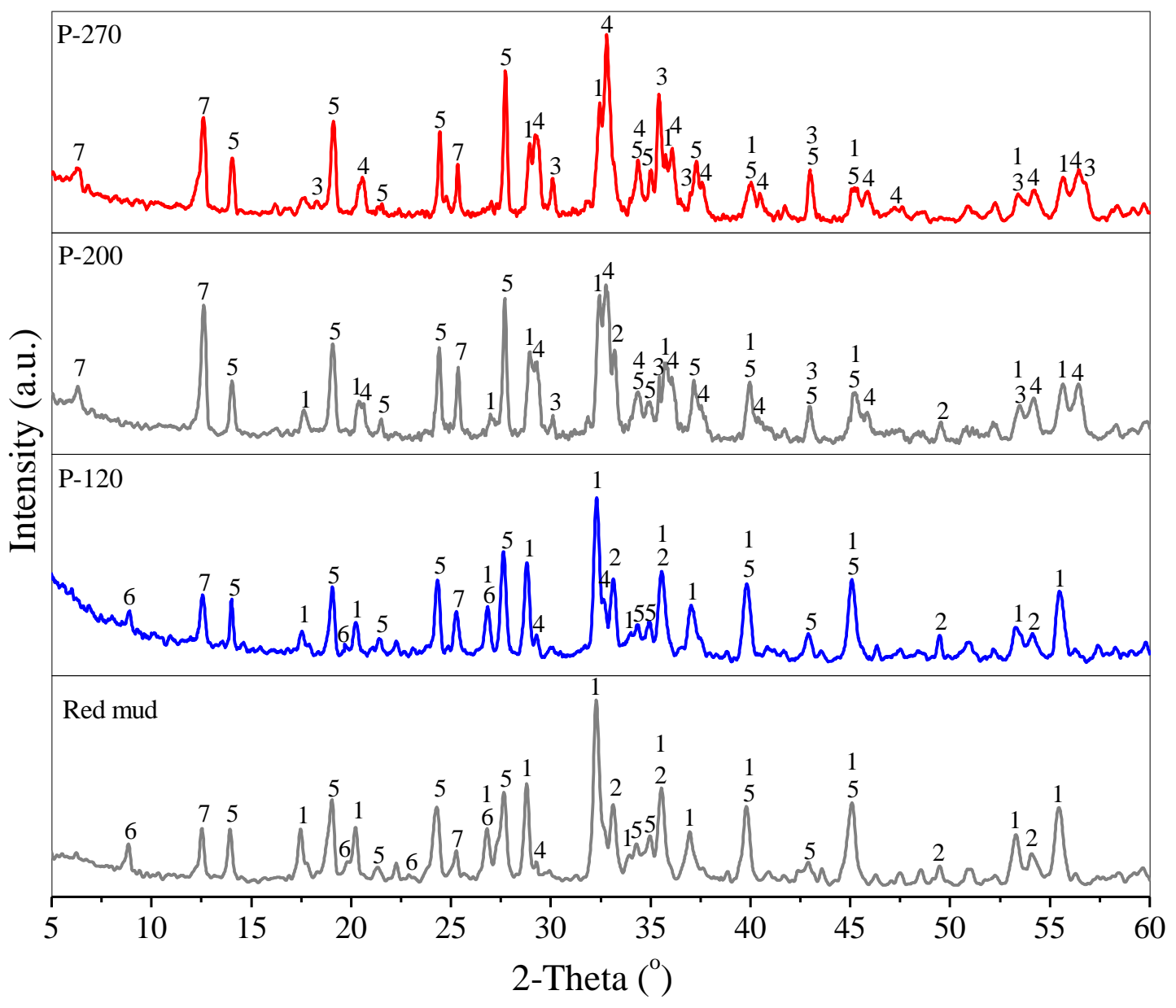

Figure 1. X-ray powder diffraction (XRD) patterns of the red mud, P-120, P-200 and P-270. In the figure, the peak was numbered: 1 : andradite; 2 : hematite; 3 : magnetite; 4 : Morimotoite; 5 : cancrinite; 6 : muscovite; 7: clinochlore.

When the temperature was increased to $270{ }^{\circ} \mathrm{C}$, the major peaks of andradite and hematite decreased, while the peaks of morimotoite and magnetite increased. By increasing temperature, the dissolution rates of $\mathrm{Al}$ and $\mathrm{Si}$ were greatly enhanced [29], which accelerated the dissolution of Si/Al coating on the surface of andradite and hematite. Accordingly, the transformation of andradite and hematite into morimotoite and magnetite was promoted.

The formation of magnetite in P-200 and P-270 was accompanied by considerable changes in magnetic behavior. Red mud was weakly magnetized (Figure 2A) and not magnetically separated (Figure 2B). Similar to red mud, P-120, prepared at a hydrothermal temperature of $120^{\circ} \mathrm{C}$, showed a weak magnetic response due to the lack of magnetic species (e.g., magnetite). When the red mud was treated at $200{ }^{\circ} \mathrm{C}$, the prepared P-200 exhibited magnetization of $4.1 \mathrm{Am}^{2} / \mathrm{kg}$, which had a magnetic response and can be magnetically separated from liquid fraction after use (Figure 2B). As the temperature increased to $270{ }^{\circ} \mathrm{C}$, the saturation magnetization of P-270 further increased to $11.9 \mathrm{Am}^{2} / \mathrm{kg}$. This finding was consistent with the presence of magnetite in P-200 and P-270, as shown in Figure 1. 


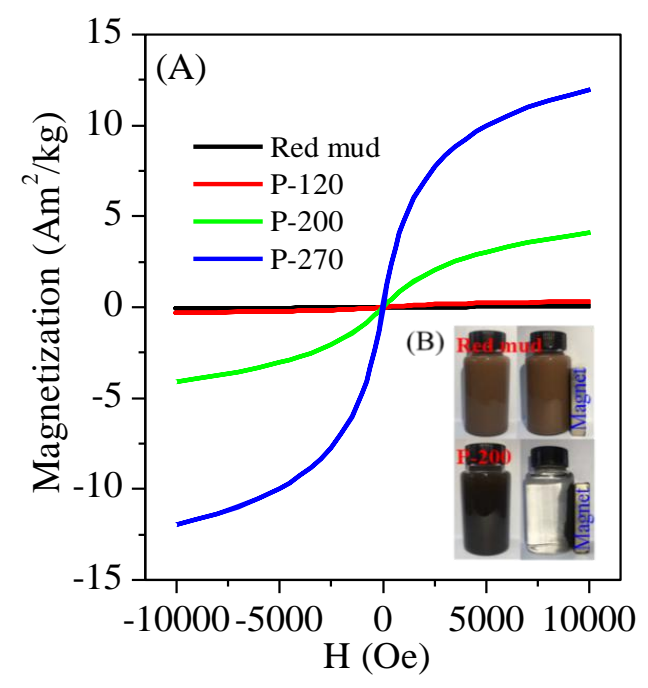

Figure 2. Magnetic hysteresis curves of red mud, P-120, P-200, and P-270.

The dissolution of muscovite and andradite in red mud after hydrothermal treatment indicated the difference in the composition of the prepared adsorbents. As shown in Figure 3A, the Si content was $10.7 \mathrm{wt} . \%$ for red mud, which slightly decreased to $9.6 \mathrm{wt} . \%$ for P-120. Accordingly, the Si concentration in the supernatant of P-120 was $24.1 \mathrm{mg} / \mathrm{L}$. The loss of Si in P-120 was subjected to the dissolution of Si-containing minerals, such as muscovite and andradite.
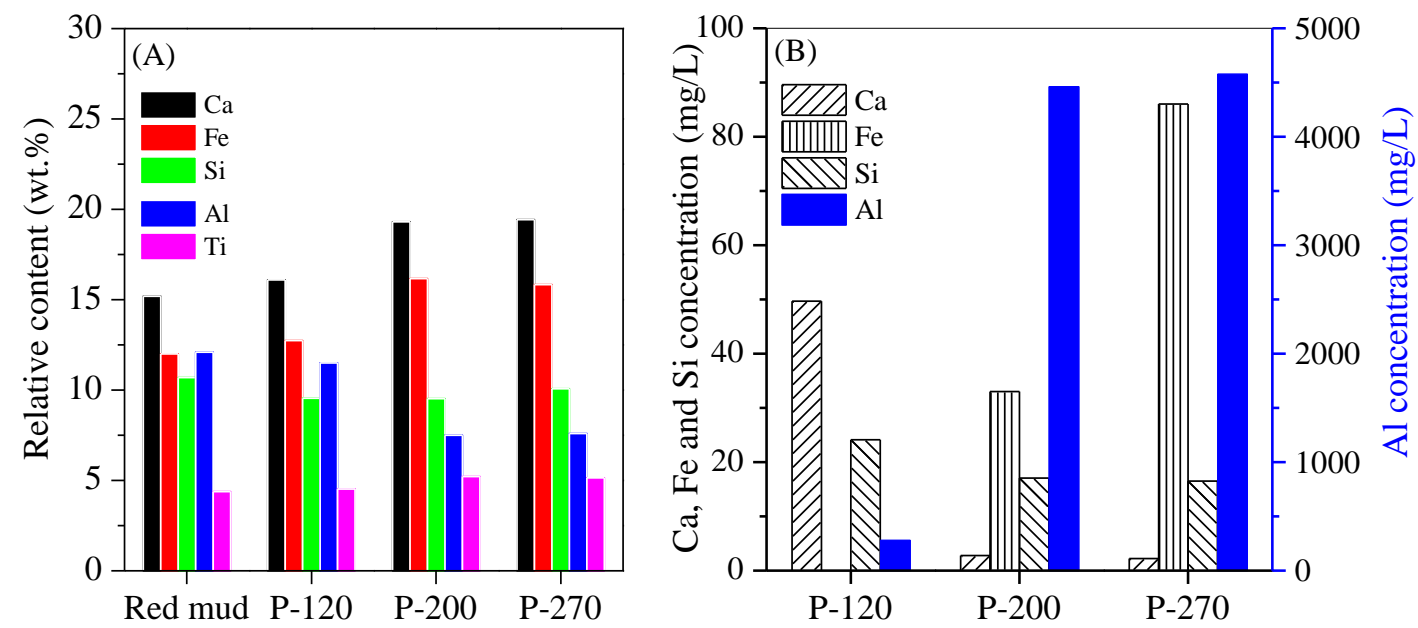

Figure 3. (A) Composition of red mud, P-120, P-200, and P-270, and (B) the major cationic concentrations in the supernatant after hydrothermal treatment.

When the temperature increased from $120^{\circ} \mathrm{C}$ to $200{ }^{\circ} \mathrm{C}$, the Si content remained unchanged, and the contents of both $\mathrm{Ca}$ and Fe increased from $16.1 \mathrm{wt} . \%$ and $12.7 \mathrm{wt} . \%$ for P-120 to $19.3 \mathrm{wt} . \%$ and $16.2 \mathrm{wt} . \%$ for P-200. In contrast, the Al content dramatically decreased from $12.1 \mathrm{wt} . \%$ for P-120 to $7.5 \mathrm{wt} . \%$ for P-200. This finding was attributed to the reductive dissolution of muscovite and andradite. When the structural $\mathrm{Fe}$ in the muscovite and andradite was reduced to $\mathrm{Fe}^{2+}$ by ascorbic acid, dissolution of muscovite and andradite occurred, followed by a release of $\mathrm{Al}$ into the liquid solution. The released $\mathrm{Al}$ was rapidly converted into $\mathrm{Al}(\mathrm{OH})_{4}{ }^{-}$under alkaline conditions, and coordinated to the surface sites of residual minerals [16]. However, abundant $\mathrm{OH}^{-}$was present in the liquid solution and competed with the coordinated $\mathrm{Al}(\mathrm{OH})_{4}{ }^{-}$via ion exchange reaction, which led to release of $\mathrm{Al}(\mathrm{OH})_{4}{ }^{-}$into the liquid solution. Thus, the high-loss of $\mathrm{Al}$ in P-200 was observed. Furthermore, the Al concentration in the supernatant was $281.6 \mathrm{mg} / \mathrm{L}$ for P-120, and was considerably higher for P-200 (4466 mg/L), which 
was consistent with the loss of $\mathrm{Al}$ in P-200 in comparison to that of P-120. This finding indicates that the dissolution of muscovite and andradite accelerated when the temperature was above $200{ }^{\circ} \mathrm{C}$. With the temperature increasing from $200{ }^{\circ} \mathrm{C}$ to $270{ }^{\circ} \mathrm{C}, \mathrm{P}-270$ showed a similar composition to P-200 except that the Fe content was slightly decreased from $16.2 \mathrm{wt} . \%$ for P-200 to $15.8 \mathrm{wt} . \%$ for P-270. Accordingly, the Fe concentration in the supernatant increased from $33 \mathrm{mg} / \mathrm{L}$ for P-200 to $86 \mathrm{mg} / \mathrm{L}$ for P-270. Muscovite was completely dissolved with the temperature increasing to $200^{\circ} \mathrm{C}$. Thus, the loss of Fe in P-270 was subjected to the release of $\mathrm{Fe}^{2+}$ via the reduction of structural $\mathrm{Fe}$ in andradite.

The major iron-bearing minerals in red mud were andradite and hematite. During the hydrothermal process, muscovite was dissolved under alkaline conditions by increasing the temperature to $200^{\circ} \mathrm{C}$. When ascorbic acid was added, it has the ability to provide electrons to the structural $\mathrm{Fe}$ in andradite and hematite with the formation of $\mathrm{Fe}^{2+}$ and dehydroascorbic acid (DHA) [21]. This led to the reductive dissolution of andradite and hematite (Equation (8)). During the dissolution of muscovite, andradite, hematite, $\mathrm{Ca}, \mathrm{Fe}, \mathrm{Si}$, and $\mathrm{Al}$ were released into the liquid fraction (Figure 4 (Step 1)). Simultaneously, ascorbic acid also reacted with dissolved oxygen, which accelerated the consumption of ascorbic acid. When ascorbic acid was exhausted, extra dissolved oxygen was left. Under the alkaline conditions, the released $\mathrm{Fe}^{2+}$ was rapidly hydrolyzed to $\mathrm{Fe}(\mathrm{OH})_{2}$ (Equation (9)), which was further reoxidized to $\mathrm{Fe}^{3+}$ by the dissolved oxygen (Equation (10) and Figure 4 (Step 2)), and coprecipitated with adjacent $\mathrm{Fe}^{2+}$ to form $\mathrm{Fe}_{3} \mathrm{O}_{4}$ (Equation (11) and Figure 4 (Step 3)) [30,31]:

$$
\begin{gathered}
2 \mathrm{Fe}^{3+}+\mathrm{HA} \rightarrow 2 \mathrm{Fe}^{2+}+\mathrm{DHA}, \\
\mathrm{Fe}^{2+}+2 \mathrm{OH}^{-} \rightarrow \mathrm{Fe}(\mathrm{OH})_{2}, \\
4 \mathrm{Fe}(\mathrm{OH})_{2}+\mathrm{O}_{2}+2 \mathrm{H}_{2} \mathrm{O} \rightarrow 4 \mathrm{Fe}(\mathrm{OH})_{3}, \\
\mathrm{Fe}(\mathrm{OH})_{2}+2 \mathrm{Fe}(\mathrm{OH})_{3} \rightarrow \mathrm{Fe}_{3} \mathrm{O}_{4}+4 \mathrm{H}_{2} \mathrm{O},
\end{gathered}
$$

Moreover, the generated $\mathrm{Fe}^{2+}$ was also involved in the crystallization of morimotoite (Figure 4 (Step 4)). In the absence of $\mathrm{Fe}$, the released $\mathrm{Ca}, \mathrm{Si}$, and $\mathrm{Al}$ were recrystallized in the formation of cancrinite (Figure 4 (Step 5)) [32].

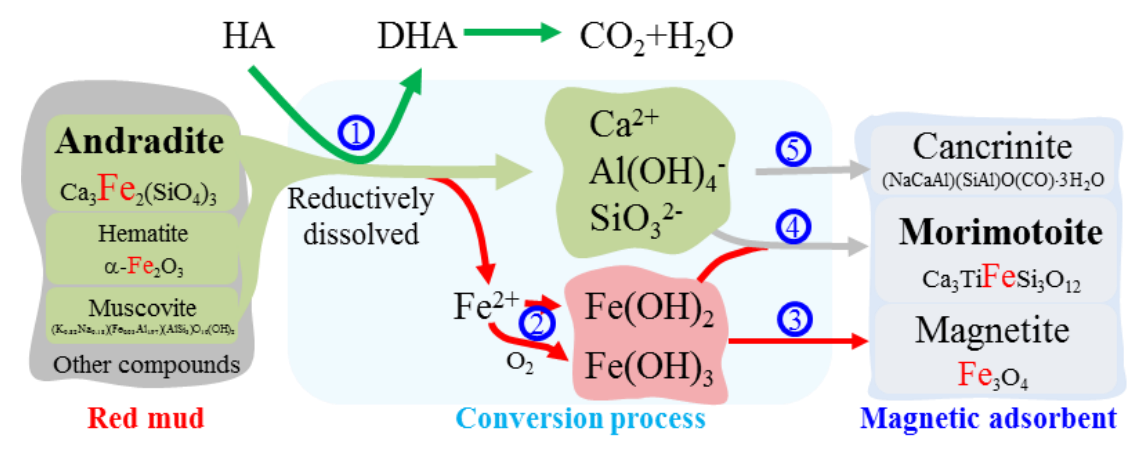

Figure 4. The proposed conversion route of iron mud into magnetic adsorbent. Step 1 represents the reductive dissolution of red mud; Step 2 represents the oxidization of ferrous Fe; Steps 3 to 5 represent the crystallization of magnetite, morimotoite, and cancrinite, respectively.

\subsection{Morphology}

The morphologies of red mud and the prepared adsorbents were shown in Figure 5. The red mud was an amorphous agglomerate with small particles on the surface (Figure 5A). P-120 showed a similar morphology to the red mud (Figure 5B). When the temperature reached $200{ }^{\circ} \mathrm{C}, \mathrm{P}-200$ exhibited fine particles with the size of $0.2-2 \mu \mathrm{m}$ (Figure 5C), which was related to the dissolution of muscovite and andradite in red mud. Compared to P-200, a new octahedron with the size of 1-4 $\mu \mathrm{m}$ belonged to the inverse spinel $\mathrm{Fe}_{3} \mathrm{O}_{4}$ [33], indicating that the high temperature promoted the crystal growth of magnetite. 

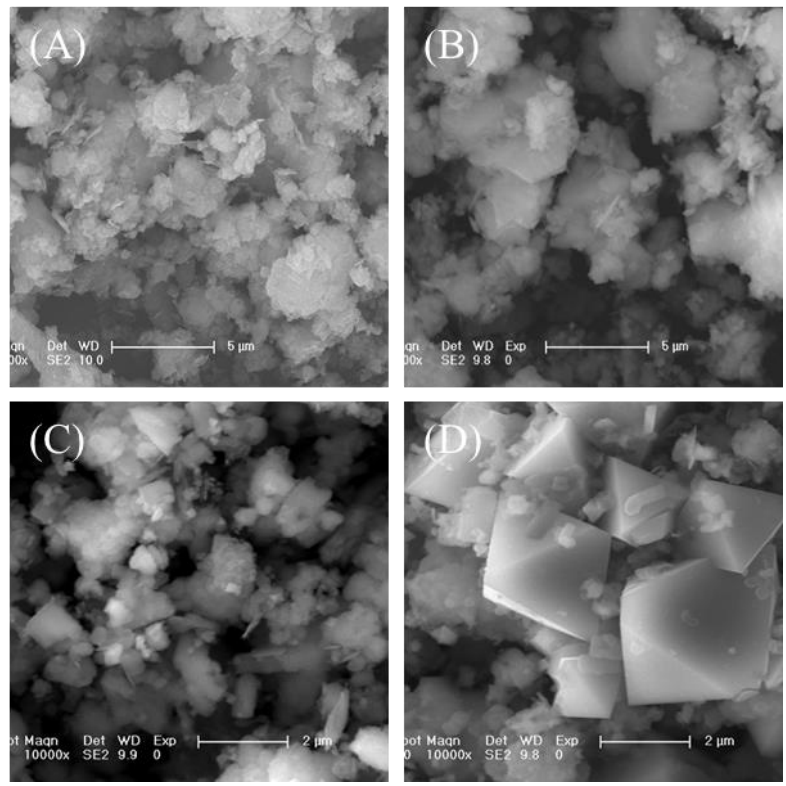

Figure 5. Scanning electron microscopy (SEM) images of (A) red mud, (B) P-120, (C) P-200, and (D) P-270.

\subsection{Adsorption}

$\mathrm{Zn}^{2+}$ is a common heavy metal ion, which is widely distributed in the wastewater from smelting, electroplating, and steel rolling industries. Thus, the adsorption performance of red mud and the prepared adsorbents on $\mathrm{Zn}^{2+}$ were investigated. As shown in Figure 6, the adsorption of $\mathrm{Zn}^{2+}$ was ranked in the following order: red mud $<\mathrm{P}-120<\mathrm{P}-270<\mathrm{P}-200$. The adsorption data was fitted with the non-linear Langmuir and Freundlich models, respectively, and the results showed that the regression coefficient values $\left(R^{2}\right)$ of Langmuir model were approximately 0.99 for red mud and the three adsorbents (Table 1), which exceeded those of the Freundlich model. This finding indicated that the red mud and the prepared adsorbents have an energetically homogeneous surface [34] for the adsorption of $\mathrm{Zn}^{2+}$. P-200 showed the desirable adsorption capacity for $\mathrm{Zn}^{2+}(89.6 \mathrm{mg} / \mathrm{g})$, higher than that of red mud, P-120, P-270, and other reported magnetic adsorbents, such as graphene oxide $(73 \mathrm{mg} / \mathrm{g})$ [35], magnetic nano-silicon materials $(51.2 \mathrm{mg} / \mathrm{g})$ [36], and dry algae $(60 \mathrm{mg} / \mathrm{g})$ [37]. Therefore, P-200 has great potential for $\mathrm{Zn}^{2+}$ adsorption.

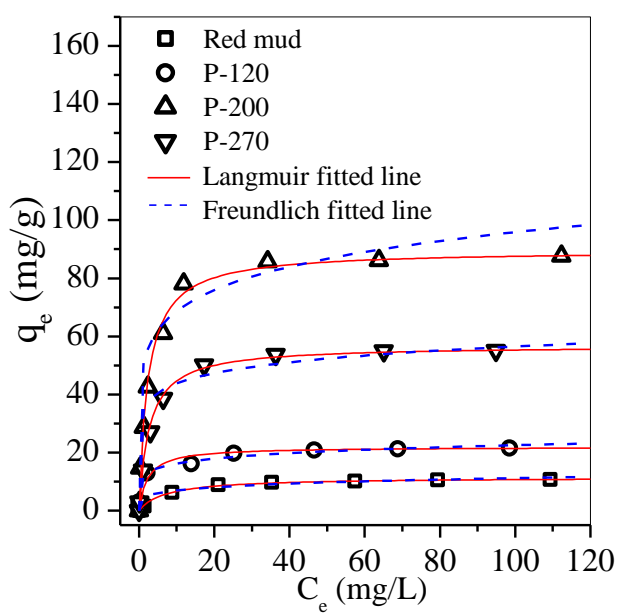

Figure 6. Adsorption isotherm of $\mathrm{Zn}^{2+}$ on red mud, P-120, P-200, and P-270. Experimental conditions: equilibrium time: $12 \mathrm{~h}$, P-200 dosage: $0.01 \mathrm{~g}$, initial $\mathrm{pH}: 4$. 
Table 1. Parameters of the isotherm models and the surface sites concentrations of red mud and the obtained adsorbents.

\begin{tabular}{cccccccc}
\hline \multirow{2}{*}{ Adsorbent } & \multicolumn{3}{c}{ Langmuir } & \multicolumn{3}{c}{ Freundlich } & $\boldsymbol{H}_{\mathbf{s}}$ \\
\cline { 2 - 8 } & $\boldsymbol{q}_{\mathbf{m} / \mathbf{( m g} / \mathbf{g})}$ & $\boldsymbol{K}_{\mathrm{L}} / \mathbf{( L / m g )}$ & $\boldsymbol{R}^{\mathbf{2}}$ & $\left.\boldsymbol{K}_{\mathbf{F}} / \mathbf{( m g} / \mathbf{g}\right)$ & $\mathbf{1 / n}$ & $\boldsymbol{R}^{\mathbf{2}}$ & $\mathbf{m m o l} \mathbf{g}$ \\
\hline Red mud & 11.43 & 0.14 & 0.998 & 4.36 & 0.2 & 0.846 & 0.51 \\
P-120 & 21.91 & 0.37 & 0.998 & 11.57 & 0.15 & 0.941 & 1.19 \\
P-200 & 89.61 & 0.44 & 0.998 & 49.26 & 0.11 & 0.715 & 4.35 \\
P-270 & 56.79 & 0.42 & 0.997 & 33.98 & 0.12 & 0.762 & 3.29 \\
\hline
\end{tabular}

The adsorption capacity of $\mathrm{Zn}^{2+}$ was in agreement with the number of surface coordination sites on red mud and the three adsorbents, which could be determined by $H_{\mathrm{s}}$ with the Gran method. As shown in Figure 7 and Table $1, H_{\mathrm{S}}$ could be listed in the following order: red mud $<$ P- $120<$ P-270 $<$ P-200, which was consistent with the adsorption capacities of $\mathrm{Zn}^{2+}$ on these adsorbents. $\mathrm{P}-200$ showed the optimal $H_{\mathrm{S}}$ of $4.35 \mathrm{mmol} / \mathrm{g}$, indicating that it had sufficient surface coordination sites for $\mathrm{Zn}^{2+}$ adsorption.

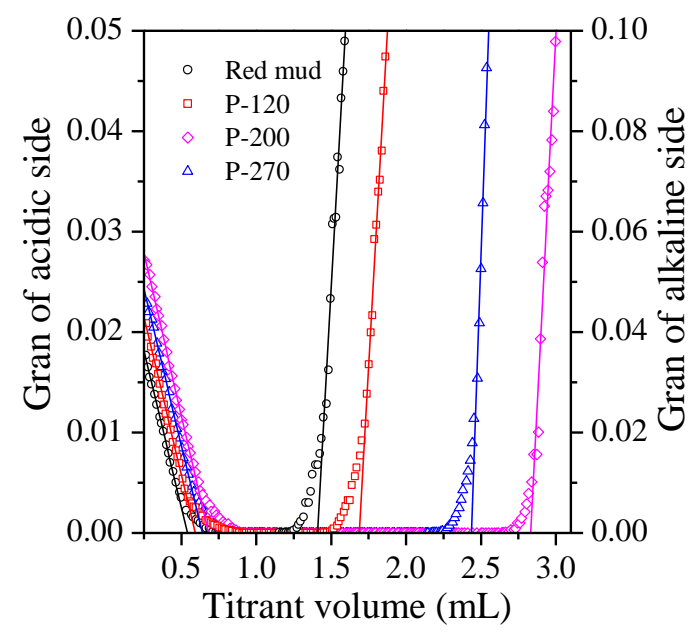

Figure 7. Gran plots of red mud, P-120, P-200, and P-270.

The distribution coefficient $\left(K_{\mathrm{d}}\right)$ was a useful index for comparing the adsorption capacities of red mud and the obtained adsorbents for $\mathrm{Zn}^{2+}$ under the same experimental condition [38,39], and calculated according to the following equation:

$$
K_{\mathrm{d}}=\frac{q_{\mathrm{e}}}{C_{\mathrm{e}}}
$$

where $q_{\mathrm{e}}$ is the amount of $\mathrm{Zn}^{2+}$ adsorbed on red mud or the obtained adsorbents $(\mathrm{mg} / \mathrm{g})$, and $C_{\mathrm{e}}$ is the equilibrium concentration of $\mathrm{Zn}^{2+}$ in the solution.

As shown in Figure 8A, $K_{d}$ decreased with the increase of the initial concentration of $\mathrm{Zn}^{2+}$. Generally, at a high initial concentration of $\mathrm{Zn}^{2+}$, the surface sites of P-200 became saturated with $\mathrm{Zn}^{2+}[39,40]$, which caused large number of unabsorbed $\mathrm{Zn}^{2+}$ remaining in the liquid fraction and apparently exhibited low $K_{\mathrm{d}}$ (Figure 8A and Table 2). However, at a low initial concentration of $\mathrm{Zn}^{2+}$, P-200 showed a high value of $K_{d}$ in comparison with P-120, P-270 and commercial adsorbents (Table 2), such as graphene oxide [36] and Tunisian smectite [41], demonstrating that P-200 had desirable performance for sorption of $\mathrm{Zn}^{2+}$. Other adsorbents, such as magnetic core-silica shell particles [36], dry algae [37], and magnetic modified chitosan [42], showed very low $K_{d}$ (Table 2), indicating that they were fairly ineffective for $\mathrm{Zn}^{2+}$ adsorption. 

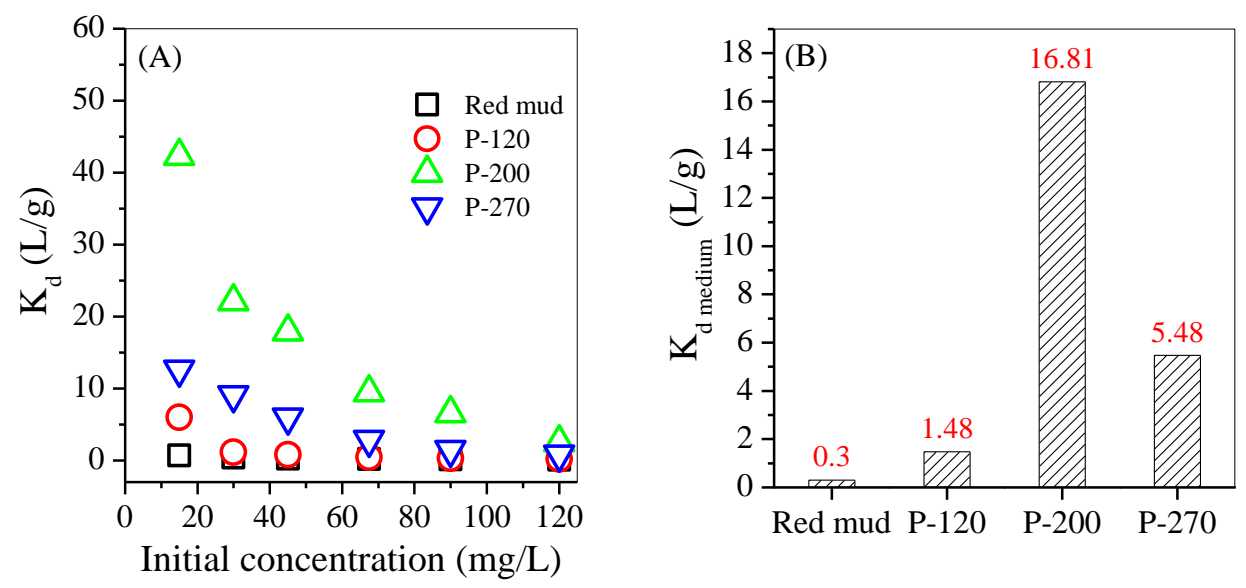

Figure 8. (A) $K_{d}$ and (B) $K_{d}$ medium values of $Z n 2+$ on the red mud, P-120, P-200, and P-270.

Table 2. Comparison of distribution coefficients of $\mathrm{Zn}^{2+}$ on the red mud, P-120, P-200, P-270, and other adsorbents.

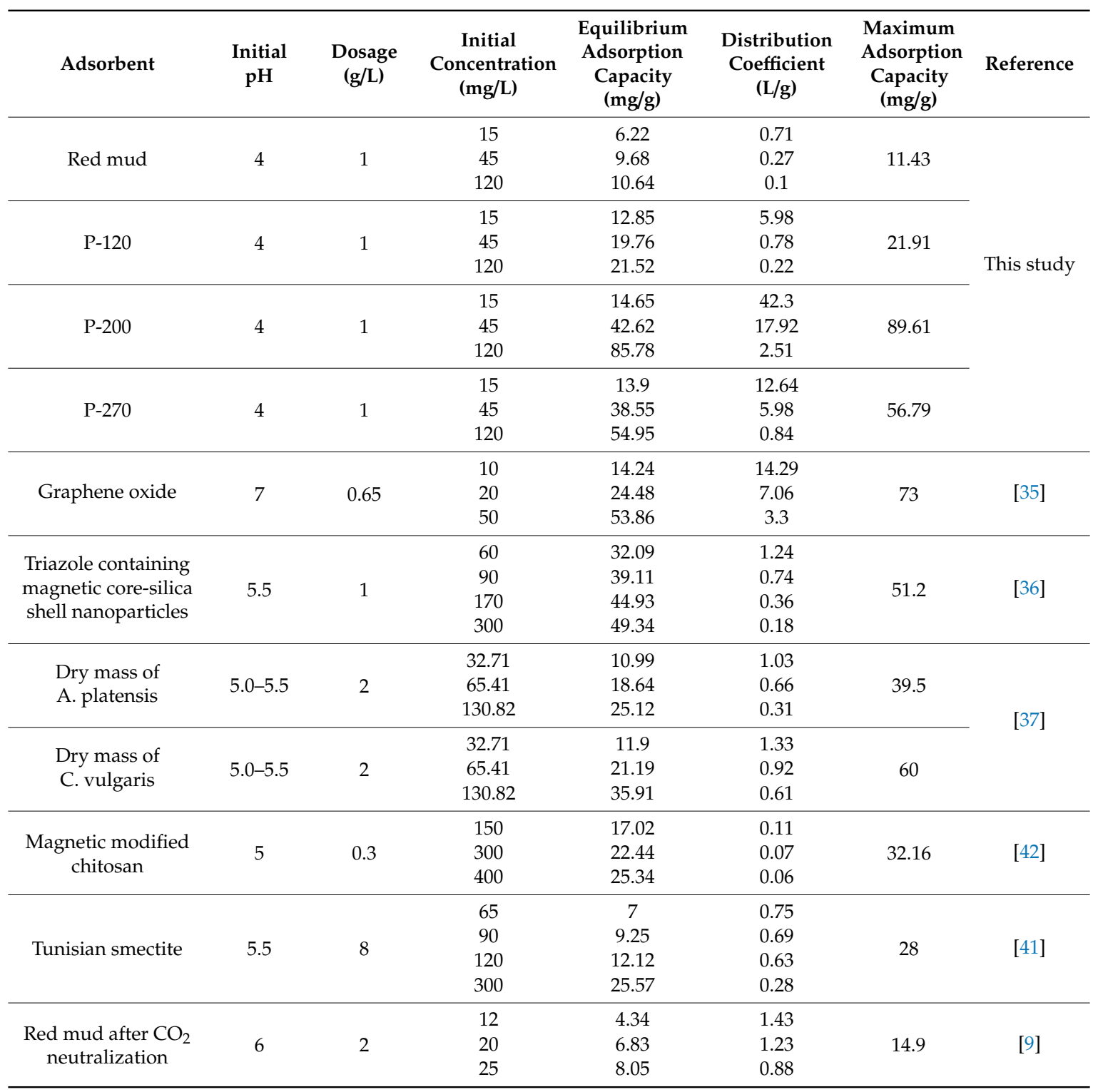


The plots of adsorption capacity versus equilibrium concentration in solution did not yield a straight line (Figure $8 \mathrm{~A})$. Thus, an average $K_{\mathrm{d}}$ value $\left(K_{\mathrm{d} \text { medium }}\right)$ was calculated according to the method of $\mathrm{Lu}$ and $\mathrm{Xu}$ [43] and used to compare the adsorption performance of red mud and the obtained adsorbents for $\mathrm{Zn}^{2+}$ adsorption. As shown in Figure $8 \mathrm{~B}, \mathrm{~K}_{\mathrm{d}}$ medium of $\mathrm{Zn}^{2+}$ on red mud and the obtained adsorbents were in the following order: P-200 > P-270 > P-120 > red mud, which was in agreement with the order of the surface site concentrations and the maximum adsorption capacities of red mud and the obtained adsorbents.

As shown in Table 2, $K_{d}$ of raw red mud and the $\mathrm{CO}_{2}$ neutralized red mud [9] were similar at the low initial concentration of $\mathrm{Zn}^{2+}$, demonstrating that the method of $\mathrm{CO}_{2}$ neutralization for red mud treatment was inefficient. However, $K_{\mathrm{d}}$ of red mud dramatically increased from $0.71 \mathrm{~L} / \mathrm{g}$ to $42.3 \mathrm{~L} / \mathrm{g}$ after hydrothermal treatment at $200{ }^{\circ} \mathrm{C}$. The improvement of $K_{\mathrm{d}}$ value indicated enhancement of adsorption affinity and adsorption capacity of P-200 [44]. Thus, the hydrothermal method was better than that of $\mathrm{CO}_{2}$ neutralization for improving the adsorption performance of red mud.

XPS experiments were conducted to characterize P-200 before and after $\mathrm{Zn}^{2+}$ adsorption. As shown in Figure 9A, the spectrum of P-200 contained the typical peaks of $\mathrm{Al}, \mathrm{Si}, \mathrm{Ca}, \mathrm{O}, \mathrm{Fe}$, and $\mathrm{Na}$. After $\mathrm{Zn}^{2+}$ adsorption, the peak of $\mathrm{Na} 1 \mathrm{~s}$ at $1072 \mathrm{eV}$ disappeared (Figure $9 \mathrm{~A}$ ), and new peaks at the binding energies of $1020.7 \mathrm{eV}$ and $1043.8 \mathrm{eV}$ (Figure 9B) belonged to $\mathrm{Zn}^{2+}$ [45]. This demonstrated that $\mathrm{Zn}^{2+}$ was adsorbed on P-200, and that $\mathrm{Na}^{+}$was released from P-200. During the adsorption, the amount of $\mathrm{Na}^{+}$desorbed from P-200 showed a positive correlation with the amount of adsorbed $\mathrm{Zn}^{2+}$ on P-200 (Figure 9C). This confirmed that the adsorption of $\mathrm{Zn}^{2+}$ on P-200 was dominated by cationic exchange.
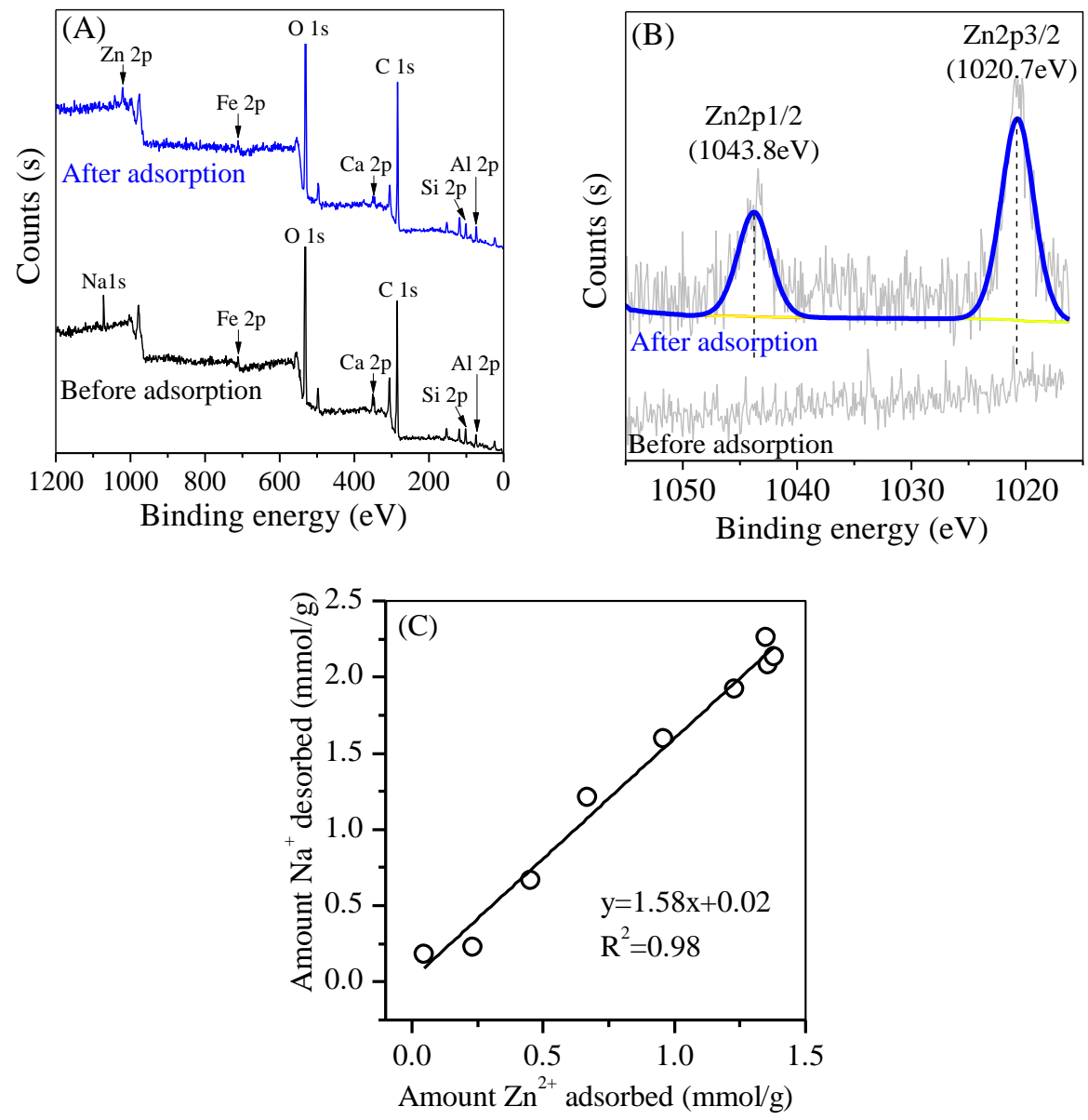

Figure 9. (A) Full range and (B) Zn 2p XPS spectra of P-200 before and after $\mathrm{Zn}^{2+}$ adsorption, and (C) amount of $\mathrm{Na}^{+}$desorbed as affected by $\mathrm{Zn}^{2+}$ adsorption on P-200. Experimental conditions: equilibrium time: $12 \mathrm{~h}$, P-200 dosage: $0.01 \mathrm{~g}$, initial $\mathrm{pH}: 4$. 
$\mathrm{P}-200$ was a mixture of magnetite, hematite and $\mathrm{Si} / \mathrm{Al}$ compounds, and exhibited functional sites $\equiv \mathrm{SO}^{-}$on its surface ( $\mathrm{S}$ representing $\mathrm{Fe}, \mathrm{Si}$, or $\mathrm{Al}$ ). In P-200 synthesis, $\mathrm{Na}^{+}$attached to the surface sites to form $\equiv \mathrm{SO}^{-} \mathrm{Na}^{+}$with the addition of $\mathrm{NaOH}$, which was replaced by $\mathrm{H}^{+}$when $\mathrm{pH}$ decreased (Equation (3)). Therefore, both $\mathrm{Na}^{+}$and $\mathrm{H}^{+}$attached on P-200 surface in $\mathrm{Zn}^{2+}$ adsorption. $\mathrm{Zn}^{2+}$ was divalent-charged, which showed higher affinity to $\equiv \mathrm{SO}^{-}$than monovalent $\mathrm{Na}^{+}$and $\mathrm{H}^{+}[46]$, and the surface-bound $\mathrm{Na}^{+}$or $\mathrm{H}^{+}$were subsequently replaced (Equations (13) and (14)). The $\mathrm{pH}$ of the solution was equilibrated to 6.3, in which $\mathrm{Zn}$ was predominated in the form of $\mathrm{Zn}^{2+}$ and $\mathrm{ZnOH}^{+}$[47]. Thus, zinc adsorption on P-200 appeared to occur via exchange of $\mathrm{Zn}^{2+}$ and $\mathrm{ZnOH}^{+}$with surface-bond $\mathrm{Na}^{+}$and $\mathrm{H}^{+}$(Equations (15) and (16)). A similar observation was reported in $\mathrm{Zn}^{2+}$ adsorption on groundwater treatment sludge, which had the similar $\equiv \mathrm{SO}^{-}$sites [23]. Of the three obtained adsorbents, $\mathrm{P}-200$ had the optimal surface sites concentration $(H \mathrm{~s})$, and thus exhibited the highest adsorption capacity.

$$
\begin{gathered}
2 \equiv \mathrm{SO}^{-} \mathrm{Na}^{+}+\mathrm{Zn}^{2+} \leftrightarrow \equiv \mathrm{SO}_{2}{ }_{2} \mathrm{Zn}^{2+}+2 \mathrm{Na}^{+} \\
2 \equiv \mathrm{SO}^{-} \mathrm{H}^{+}+\mathrm{Zn}^{2+} \leftrightarrow \equiv \mathrm{SO}^{-}{ }_{2} \mathrm{Zn}^{2+}+2 \mathrm{H}^{+} \\
\equiv \mathrm{SO}^{-} \mathrm{H}^{+}+\mathrm{Zn}^{2+}+\mathrm{H}_{2} \mathrm{O} \leftrightarrow \equiv \mathrm{SO}^{-}(\mathrm{ZnOH})^{+}+2 \mathrm{H}^{+} \\
\equiv \mathrm{SO}^{-} \mathrm{Na}^{+}+\mathrm{Zn}^{2+}+\mathrm{H}_{2} \mathrm{O} \leftrightarrow \equiv \mathrm{SO}^{-}(\mathrm{ZnOH})^{+}+\mathrm{Na}^{+}+\mathrm{OH}^{-}
\end{gathered}
$$

The operation cost of the adsorbent P-200 for $\mathrm{Zn}^{2+}$ adsorption was important in wastewater treatment. Synthesis of one ton of magnetic adsorbent needed 0.01 ton of ascorbic acid, 0.27 ton of caustic soda, and $45 \mathrm{~kW}$ h power, and the total production cost was US\$158.8. Disposal of red mud accounted for about $5 \%$ of alumina production [48], and the alumina price was US $\$ 439$ per ton in China [49]. The disposal cost of red mud was nearly US $\$ 22$ per ton, which could be deducted from the production cost of P-200. Thus, the net cost of P-200 production was about US\$ 136.8 per ton. For treating $\mathrm{Zn}^{2+}$-containing wastewater, the operation cost of P-200 was approximately US\$ 1.45 per ton, lower than the widely used adsorbents, such as granular active carbon [50] and zero-valent nanometer iron [51], indicating that the application of P-200 for heavy metal removal was economically feasible.

\section{Conclusions}

Red mud is an alkaline solid waste and abundant in andradite, muscovite, hematite, and cancrinite. Red mud was converted to a magnetic adsorbent via a facile hydrothermal route using ascorbic acid as reducing agent. With hydrothermal treatment, the magnetic adsorbent was formed in the following steps: (1) the dissolution of muscovite under alkaline conditions, (2) the reductive dissolution of andradite with the generation of $\mathrm{Fe}^{2+}$, (3) the reoxidization of $\mathrm{Fe}^{2+}$ to $\mathrm{Fe}^{3+}$ by dissolved oxygen and the coprecipitation of $\mathrm{Fe}^{3+}$ and $\mathrm{Fe}^{2+}$ in the form of $\mathrm{Fe}_{3} \mathrm{O}_{4}$, and (4) the crystallization of cancrinite and morimotoite. By increasing the hydrothermal temperature, the reductive dissolution of andradite was promoted and the crystal size of magnetite was enlarged. When the temperature increased to $200{ }^{\circ} \mathrm{C}$, the prepared P-200 showed a well saturation magnetization of $4.1 \mathrm{Am}^{2} / \mathrm{kg}$, an ideal adsorption capacity of $\mathrm{Zn}^{2+}(89.6 \mathrm{mg} / \mathrm{g})$, and a high average $K_{\mathrm{d}}$ value of $16.8 \mathrm{~L} / \mathrm{g}$, and thus exhibited desirable $\mathrm{Zn}^{2+}$ adsorption under real-world conditions. Cationic exchange was the dominated mechanism for $\mathrm{Zn}^{2+}$ adsorption on P-200. Those advantages indicated that P-200 was a promising adsorbent for the treatment of $\mathrm{Zn}^{2+}$ containing wastewater.

Author Contributions: Conceptualization, S.Z.; methodology, S.Z. and L.Z.; software, W.D. and K.L.; validation, D.B., J.Y., and X.Z.; formal analysis, Y.Q. and H.M.; investigation, Y.Y.; writing-original draft preparation, W.D.; writing-review and editing, Y.Y.; funding acquisition, D.B. and X.Z.

Funding: This work was partially funded by the National Natural Science Foundation of China (Grant Nos. 51578118, 51678273, 51878134, and 51878133). Experimental sessions in Kulunqi plant were supported by the Science and Technology Program of Jilin Province (Granted No. 20190303001SF).

Conflicts of Interest: The authors declare no conflict of interest. 


\section{References}

1. Klauber, C.; Gräfe, M.; Power, G. Bauxite residue issues: II. options for residue utilization. Hydrometallurgy 2011, 108, 11-32. [CrossRef]

2. Ye, N.; Yang, J.; Liang, S.; Hu, Y.; Hu, J.; Xiao, B.; Huang, Q. Synthesis and strength optimization of one-part geopolymer based on red mud. Constr. Build. Mater. 2016, 111, 317-325. [CrossRef]

3. Jian, H.; Jie, Y.; Zhang, J.; Yu, Y.; Zhang, G. Synthesis and characterization of red mud and rice husk ash-based geopolymer composites. Cement Concr. Compos. 2013, 37, 108-118.

4. Davris, P.; Balomenos, E.; Panias, D.; Paspaliaris, I. Selective leaching of rare earth elements from bauxite residue (red mud), using a functionalized hydrophobic ionic liquid. Hydrometallurgy 2016, 164, 125-135. [CrossRef]

5. Sushil, S.; Batra, V.S. Catalytic applications of red mud, an aluminium industry waste: A review. Appl. Catal. B Environ. 2008, 81, 64-77. [CrossRef]

6. Paramgura, R.K.; Rath, P.C.; Misra, V.N. Trends in red mud utilization-A review. Miner. Process. Extr. Metall. Rev. 2004, 26, 1-29. [CrossRef]

7. Wang, S.; Ang, H.M.; Tadé, M.O. Novel applications of red mud as coagulant, adsorbent and catalyst for environmentally benign processes. Chemosphere 2008, 72, 1621-1635. [CrossRef] [PubMed]

8. Zhang, Y.; Wang, Y.; Meng, X.; Zheng, L.; Gao, J. The Suppression Characteristics of $\mathrm{NH}_{4} \mathrm{H}_{2} \mathrm{PO}_{4} / \mathrm{Red} \mathrm{Mud}$ Composite Powders on Methane Explosion. Appl. Sci. 2018, 8, 1433. [CrossRef]

9. Sahu, R.C.; Patel, R.; Ray, B.C. Adsorption of $\mathrm{Zn}(\mathrm{II})$ on activated red mud: Neutralized by $\mathrm{CO}_{2}$. Desalination 2011, 266, 93-97. [CrossRef]

10. Wang, Y.; Yu, Y.; Li, H.; Shen, C. Comparison study of phosphorus adsorption on different waste solids: Fly ash, red mud and ferric-alum water treatment residues. J. Environ. Sci. China 2016, 50, 79-86. [CrossRef] [PubMed]

11. Busto, R.V.; Gonã§Alves, M.; Coelho, L.H. Assessment of the use of red mud as a catalyst for photodegradation of bisphenol A in wastewater treatment. Water Sci. Technol. 2016, 74, 1283-1295. [CrossRef] [PubMed]

12. Liu, Y.; Zhao, B.; Yang, T.; Wan, P.; Chen, Y.; Lv, Z. Recycling of iron from red mud by magnetic separation after co-roasting with pyrite. Thermochim. Acta 2014, 588, 11-15. [CrossRef]

13. Yang, H.; Jing, L.; Zhang, B. Recovery of iron from vanadium tailings with coal-based direct reduction followed by magnetic separation. J. Hazard. Mater. 2011, 185, 1405-1411. [CrossRef]

14. Samouhos, M.; Taxiarchou, M.; Pilatos, G.; Tsakiridis, P.; Devlin, E.; Pissas, M. Controlled reduction of red mud by $\mathrm{H}_{2}$ followed by magnetic separation. Miner. Eng. 2017, 105, 36-43. [CrossRef]

15. Sushil, S.; Alabdulrahman, A.M.; Balakrishnan, M.; Batra, V.; Blackley, R.; Clapp, J.; Hargreaves, J.; Monaghan, A.; Pulford, I.; Rico, J.; et al. Carbon deposition and phase transformations in red mud on exposure to methane. J. Hazard. Mater. 2010, 180, 409-418. [CrossRef]

16. Jianmin, Z. Ferrihydrite: Surface Structure and its Effects on Phase Transformation. Clays Clay Miner. 1994, 42, 737-746. [CrossRef]

17. Zhu, S.; Fang, S.; Huo, M.; Yu, Y.; Chen, Y.; Yang, X.; Geng, Z.; Wang, Y.; Bian, D.; Huo, H. A novel conversion of the groundwater treatment sludge to magnetic particles for the adsorption of methylene blue. J. Hazard. Mater. 2015, 292, 173-179. [CrossRef]

18. Li, X.; Liu, N.; Qi, T.; Wang, Y.; Zhou, Q.; Peng, Z.; Liu, G. Conversion of ferric oxide to magnetite by hydrothermal reduction in Bayer digestion process. Trans. Nonferr. Metals Soc. China 2015, 25, 3467-3474. [CrossRef]

19. Liu, J.; Yu, Y.; Zhu, S.; Yang, J.; Song, J.; Fan, W.; Yu, H.; Bian, D.; Huo, M. Synthesis and characterization of a magnetic adsorbent from negatively-valued iron mud for methylene blue adsorption. PLoS ONE 2018, 13, e0191229. [CrossRef]

20. Echigo, T.; Aruguete, D.M.; Murayama, M.; Hochella, M. Influence of size, morphology, surface structure, and aggregation state on reductive dissolution of hematite nanoparticles with ascorbic acid. Geochim. Cosmochim. Acta 2012, 90, 149-162. [CrossRef]

21. Hou, X.; Huang, X.; Ai, Z.; Zhao, J.; Zhang, L. Ascorbic acid/Fe@Fe $\mathrm{O}_{3}$ : A highly efficient combined Fenton reagent to remove organic contaminants. J. Hazard. Mater. 2016, 310, 170-178. [CrossRef] [PubMed]

22. Xin, N.; Shen, L.; Gu, H.; Jiang, S.; Xiao, J. Characteristics of hematite and fly ash during chemical looping combustion of sewage sludge. Chem. Eng. J. 2015, 268, 236-244. 
23. Zhu, S.; Lin, X.; Dong, G.; Yu, Y.; Yu, H.; Bian, D.; Zhang, L.; Yang, J.; Wang, X.; Huo, M. Valorization of manganese-containing groundwater treatment sludge by preparing magnetic adsorbent for $\mathrm{Cu}(\mathrm{II})$ adsorption. J. Environ. Manag. 2019, 236, 446-454. [CrossRef] [PubMed]

24. Lammers, K.; Smith, M.M.; Carroll, S.A. Muscovite dissolution kinetics as a function of $\mathrm{pH}$ at elevated temperature. Chem. Geol. 2017, 466, 149-158. [CrossRef]

25. Cao, S.; Ma, H.; Zhang, Y.; Chen, X.; Zhang, Y.; Zhang, Y. The phase transition in Bayer red mud from China in high caustic sodium aluminate solutions. Hydrometallurgy 2013, 140, 111-119. [CrossRef]

26. Zhang, R.; Zheng, S.; Ma, S.; Zhang, Y. Recovery of alumina and alkali in Bayer red mud by the formation of andradite-grossular hydrogarnet in hydrothermal process. J. Hazard. Mater. 2011, 189, 827-835. [CrossRef] [PubMed]

27. Edgar, J.; Bell, R.G.; Dirk, W.; Hubert, K. Anion-promoted cation motion and conduction in zeolites. J. Am. Chem. Soc. 2006, 128, 558-567.

28. Park, M.; Choi, C.L.; Lim, W.T.; Kim, M.C.; Choi, J.; Heo, N.H. Molten-salt method for the synthesis of zeolitic materials: I. Zeolite formation in alkaline molten-salt system. Microporous Mesoporous Mater. 2000, 37, 81-89. [CrossRef]

29. Zeng, L.; Li, Z. Dissolution Behavior of Aluminum, Silicon, and Iron of Diaspore Concentrate in $\mathrm{NaOH}-\mathrm{NaAl}(\mathrm{OH})_{4}$ Solutions at Elevated Temperature. Ind. Eng. Chem. Res. 2013, 52, 18429-18439. [CrossRef]

30. Zong, Y.; Xin, H.; Zhang, J.; Li, X.; Feng, J.; Deng, X.; Sun, Y.; Zheng, X. One-pot, template- and surfactant-free solvothermal synthesis of high-crystalline $\mathrm{Fe}_{3} \mathrm{O}_{4}$ nanostructures with adjustable morphologies and high magnetization. J. Magn Magn. Mater. 2016, 423, 321-326. [CrossRef]

31. Wang, W.; Howe, J.Y.; Gu, B. Structure and Morphology Evolution of Hematite $\left(\alpha-\mathrm{Fe}_{2} \mathrm{O}_{3}\right)$ Nanoparticles in Forced Hydrolysis of Ferric Chloride. J. Phys. Chem. C 2008, 112, 9203-9208. [CrossRef]

32. Belviso, C.; Agostinelli, E.; Belviso, S.; Cavalcante, F.; Pascucci, S.; Peddis, D.; Varvaro, G.; Fiore, S. Synthesis of magnetic zeolite at low temperature using a waste material mixture: Fly ash and red mud. Microporous Mesoporous Mater. 2015, 202, 208-216. [CrossRef]

33. Peng, D.; Beysen, S.; Li, Q.; Jian, J.; Sun, Y.; Jiwuer, J. Hydrothermal growth of octahedral $\mathrm{Fe}_{3} \mathrm{O}_{4}$ crystals. Particuology 2009, 7, 35-38. [CrossRef]

34. Rouquerol, J.; Llewellyn, P.; Rouquerol, F. Is the BET equation applicable to microporous adsorbents. Stud. Surf. Sci. Catal. 2007, 160,49-56.

35. Yang, Q.; Yang, G.; Peng, W.; Song, S. Adsorption of Zn(II) on graphene oxide prepared from low-purity of amorphous graphite. Surf. Interface Anal. 2017, 49, 398-404. [CrossRef]

36. Mokadem, Z.; Mekki, S.; Saïdi-Besbes, S.; Agusti, G.; Elaissari, A.; Derdour, A. Triazole containing magnetic core-silica shell nanoparticles for $\mathrm{Pb}^{2+}, \mathrm{Cu}^{2+}$ and $\mathrm{Zn}^{2+}$ removal. Arab. J. Chem. 2017, 10, 1039-1051. [CrossRef]

37. Ferreira, L.S.; Rodrigues, M.S.; de Carvalho, J.C.M.; Finocchio, E.; Lodi, A.; Perego, P.; Converti, A. Adsorption of $\mathrm{Ni}^{2+}, \mathrm{Zn}^{2+}$ and $\mathrm{Pb}^{2+}$ onto dry biomass of Arthrospira (Spirulina) platensis and Chlorella vulgaris. I. Single metal systems. Chem. Eng. J. 2011, 173, 326-333. [CrossRef]

38. Vikrant, K.; Kim, K.-H. Nanomaterials for the adsorptive treatment of $\mathrm{Hg}(\mathrm{II})$ ions from water. Chem. Eng. J. 2019, 358, 264-282. [CrossRef]

39. Na, C.-J.; Yoo, M.-J.; Tsang, D.C.W.; Kim, H.W.; Kim, K.H. High-performance materials for effective sorptive removal of formaldehyde in air. J. Hazard. Mater. 2019, 366, 452-465. [CrossRef]

40. Deng, Y.; Vellingiri, K.; Kim, K.-H.; Boukhvalov, D.W.; Philip, L. Activation strategies of metal-organic frameworks for the sorption of reduced sulfur compounds. Chem. Eng. J. 2018, 350, 747-756. [CrossRef]

41. Eloussaief, M.; Hamza, W.; Kallel, N.; Benzina, M. Wastewaters decontamination: Mechanisms of $\mathrm{Pb}(\mathrm{II}), \mathrm{Zn}(\mathrm{II})$, and $\mathrm{Cd}(\mathrm{II})$ competitive adsorption on tunisian smectite in single and multi-solute systems. Environ. Prog. Sustain. 2013, 32, 229-238. [CrossRef]

42. Fan, L.; Luo, C.; Lv, Z.; Lu, F.G.; Qiu, H.M. Preparation of magnetic modified chitosan and adsorption of $\mathrm{Zn}^{2+}$ from aqueous solutions. Colloids Surf. B Biointerf. 2011, 88, 574-581. [CrossRef]

43. Lu, S.G.; $\mathrm{Xu}$, Q.F. Competitive adsorption of $\mathrm{Cd}, \mathrm{Cu}, \mathrm{Pb}$ and $\mathrm{Zn}$ by different soils of Eastern China. Environ. Geol. 2009, 57, 685-693. [CrossRef] 
44. Vellingiri, K.; Kim, K.-H.; Kwon, E.E.; Deep, A.; Jo, S.H.; Szulejko, J.E. Insights into the adsorption capacity and breakthrough properties of a synthetic zeolite against a mixture of various sulfur species at low ppb levels. J. Environ. Manag. 2016, 166, 484-492. [CrossRef]

45. Biesinger, M.C.; Lau, L.W.M.; Gerson, A.R.; Smart, R.S.C. Resolving surface chemical states in XPS analysis of first row transition metals, oxides and hydroxides: Sc, Ti, V, Cu and Zn. Appl. Surf. Sci. 2010, 257, 887-898. [CrossRef]

46. Top, A.; Ülkü, S. Silver, zinc, and copper exchange in a Na-clinoptilolite and resulting effect on antibacterial activity. Appl. Clay Sci. 2004, 27, 13-19. [CrossRef]

47. Phan, T.N.T.; Louvard, N.; Bachiri, S.A.; Persello, J.; Foissy, A. Adsorption of zinc on colloidal silica, triple layer modelization and aggregation data. Colloid Surf. A 2004, 244, 131-140. [CrossRef]

48. Kumar, S.; Kumar, R.; Bandopadhyay, A. Innovative methodologies for the utilisation of wastes from metallurgical and allied industries. Resour. Conserv. Recycl. 2006, 48, 301-314. [CrossRef]

49. Sutar, H.; Mishra, S.C.; Sahoo, S.K.; Chakraverty, A.P.; Maharana, H. Progress of red mud utilization: An overview. Am. Chem. Sci. J. 2014, 4, 255-279. [CrossRef]

50. Lu, C.; Liu, C.; Rao, G.P. Comparisons of sorbent cost for the removal of $\mathrm{Ni}^{2+}$ from aqueous solution by carbon nanotubes and granular activated carbon. J. Hazard. Mater. 2008, 151, 239-246. [CrossRef]

51. Li, S.; Wang, W.; Liu, Y.; Zhang, W. Zero-valent iron nanoparticles (nZVI) for the treatment of smelting wastewater: A pilot-scale demonstration. Chem. Eng. J. 2014, 254, 115-123. [CrossRef]

(C) 2019 by the authors. Licensee MDPI, Basel, Switzerland. This article is an open access article distributed under the terms and conditions of the Creative Commons Attribution (CC BY) license (http://creativecommons.org/licenses/by/4.0/). 